\title{
Retinoic Acid Inhibits the Regulated Expression of Vascular Cell Adhesion Molecule-1 by Cultured Dermal Microvascular Endothelial Cells
}

\author{
Jens Gille, Lani L.L. Paxton, Thomas J. Lawley, S. Wright Caughman, and Robert A. Swerlick \\ Emory Skin Diseases Research Center, Department of Dermatology, Emory University School of Medicine, Atlanta, Georgia 30322
}

\begin{abstract}
The regulated expression of cell adhesion molecules (CAM) on endothelial cells is central to the pathogenesis of various inflammatory processes. Retinoic acid and synthetic derivatives have been demonstrated to exert antiinflammatory effects in cutaneous diseases. To determine modes of retinoid action in the modulation of inflammatory responses, we explored effects of all-trans-retinoic acid (t-RA) on the TNF $\alpha$ induced expression of vascular cell adhesion molecule-1 (VCAM-1), intercellular adhesion molecule-1 (ICAM-1), and E-selectin in cultured human dermal microvascular endothelial cells. Pretreatment with t-RA specifically prevented TNF $\alpha$-induced VCAM-1 expression, but not ICAM-1 and E-selectin induction. t-RA significantly reduced VCAM1-dependent $\mathrm{T}$ cell binding to $\mathrm{TNF} \alpha$-treated human dermal microvascular endothelial cells as well. This differential modulation of TNF $\alpha$-induced CAM expression by t-RA was reflected at steady state $\mathrm{mRNA}$ levels and in nuclear run-on studies. In transcriptional activation studies, the TNF $\alpha$ mediated activation of the human VCAM-1 promoter was inhibited after t-RA treatment, while the ICAM-1 promoter activation was unaffected, indicating that the selective inhibition of CAM expression is regulated in part at the level of gene transcription. Furthermore, the transcriptional inhibition by t-RA appears to be mediated by its effects upon the activation of NF- $\mathrm{KB}$-dependent complex formation. Analysis of protein-DNA binding assays revealed marked inhibition of specific NF- $\kappa \mathrm{B}$-dependent binding to the tandem NF- $\kappa$ B sites of the VCAM-1 promoter, but not to the functional NF- $\kappa$ B motif of the ICAM-1 promoter. The specific inhibition of cytokine-mediated VCAM-1 gene expression in vitro may provide a potential basis by which retinoids exert their biological effects at sites of inflammation in vivo. (J. Clin. Invest. 1997. 99:492-500.) Key words: retinoids • cytokines $\bullet$ endothelium $\bullet$ gene expression regulation $\bullet N F-\kappa B$
\end{abstract}

\section{Introduction}

As a critical cellular response to inflammation and tissue damage, the localization of circulating leukocytes to endothelium is fundamentally directed by the expression of cell adhesion mol-

Address correspondence to Robert A. Swerlick, M.D., Department of Dermatology, Emory University School of Medicine, 5014 Woodruff Memorial Research Building, 1639 Pierce Drive, Atlanta, GA 30322. Phone: 404-727-2893; FAX: 404-727-5878.

Received for publication 5 April 1995 and accepted in revised form 21 November 1996.

J. Clin. Invest.

(C) The American Society for Clinical Investigation, Inc.

0021-9738/97/02/0492/09 \$2.00

Volume 99, Number 3, February 1997, 492-500 ecules (CAMs) ${ }^{1}$ (1). Leukocyte-endothelial cell (EC) recognition and extravasation are based on a sequential series of events which require the regulated expression of multiple adhesion proteins by EC (3), including intercellular adhesion molecule-1 (ICAM-1) (2), E-selectin (3), and vascular cell adhesion molecule-1 (VCAM-1) (4). Combinatorial mechanisms involving time- and stimulus-dependent CAM expression on EC and leukocyte subsets provide both diversity and specificity in leukocyte-EC interactions (5).

Stimuli commonly found in inflammatory processes, such as the cytokines TNF $\alpha$ or IL-1, concurrently induce the expression of VCAM-1, ICAM-1, and E-selectin in a concentration- and time-dependent fashion on EC. While rapidly induced by various proinflammatory signals, E-selectin may mediate initial attachment and rolling of leukocytes before firm adhesion through interaction with carbohydrate ligands. Endothelial VCAM-1 and ICAM-1 induction are less rapid, reaching maximal levels of expression after 16-24 h. VCAM-1 primarily mediates adhesion to mononuclear leukocytes by interacting with their $\alpha 4 \beta 1$ integrin receptors. While VCAM-1 has been demonstrated to participate as a counterreceptor in rolling of certain leukocyte subsets as well as in their reversible attachment to EC, endothelial ICAM-1, which binds virtually all subsets of leukocytes via $\beta 2$-integrin receptors (CD18), has been implicated in mediating firm leukocyte adhesion and transmigration through the vessel walls.

Retinoids, a family of retinol metabolites and synthetic derivatives, are effective pharmacologic agents in the topical and systemic treatment of inflammatory cutaneous diseases, such as psoriasis and acne vulgaris (6). Established and well documented effects of retinoids include their regulation of growth and differentiation in different cell types, as well as their inhibition of tumor promotion and malignant cell proliferation (7, 8). Various cellular and molecular events by which retinoic acid (RA) modulates the differentiation state and the proliferative capacity of a variety of cell types have been elucidated previously $(9,10)$.

Among various described and documented biological effects of retinoids, the underlying mechanisms of retinoids as antiinflammatory agents are not well defined. Since the regulated expression of CAM on EC represents a central part in the initiation and maintenance of multiple acute and chronic inflammatory disorders, we hypothesized that retinoids, as potent antiinflammatory agents, may exert part of their biologic effects through modulation of the regulated CAM expression

1. Abbreviations used in this paper: CAM, cell adhesion molecule; CAT, chloramphenicol acetyl transferase; EC, endothelial cells; EMSA, electrophoretic mobility shift assay; HDMEC, human dermal microvascular endothelial cells; HUVEC, human umbilical vein EC; ICAM-1, intercellular adhesion molecule-1; NF-кB, nuclear factor$\kappa \mathrm{B}$; RA, retinoic acid; t-RA, all-trans-retinoic acid; VCAM-1, vascular cell adhesion molecule-1. 
on EC. By using dermal microvascular EC as an in vitro model, we determined the effects of all-trans-retinoic acid (t-RA) on the TNF $\alpha$-induced expression of ICAM-1, E-selectin, and VCAM-1.

We here report that t-RA specifically prevents the cytokine-induced expression of VCAM-1, but not E-selectin and ICAM-1 induction. This differential modulation of CAM expression on microvascular EC was demonstrated on both protein and steady state mRNA and in nuclear run-on levels. In addition, transcriptional activation studies provide evidence that this differential regulation of CAM induction by RA is in part transcriptionally mediated. Furthermore, we demonstrate that t-RA selectively inhibits VCAM-1-specific NF $\kappa \mathrm{B}$-dependent DNA-protein complex formation, while it has no effect on NF-кB-dependent binding within the context of the ICAM-1 gene. While trans-repression of gene transcription by retinoids has been described previously, our data provide novel evidence for retinoid-mediated selective trans-repressor activity that is mediated via interference with NF-кB-dependent VCAM-1 gene transcription. Together, these data demonstrate that one of the mechanisms by which RA exerts its antiinflammatory effects is likely via selective inhibition of VCAM-1 gene expression by EC.

\section{Methods}

Reagents and antibodies. t-RA (Sigma Chemical Co., St. Louis, MO) was dissolved in DMSO (Sigma Chemical Co.) at a concentration of $10 \mathrm{mM}$. t-RA was freshly made before each experiment and diluted in human dermal microvascular endothelial cell (HDMEC) media containing 5\% FBS (Atlanta Biologicals, Inc., Norcross, GA). Human recombinant TNF $\alpha$ was a generous gift from Genentech Corp. (South San Francisco, CA) and was added at a concentration of $500 \mathrm{U} / \mathrm{ml}$ as indicated. mAb P3C4 directed against VCAM-1 was a generous gift from Dr. Elizabeth Wayner (University of Minnesota, Minneapolis, $\mathrm{MN})$. mAb 1D6 recognizing E-selectin was kindly provided by Dr. Barry Wolitzky (Hoffman-LaRoche, Nutley, NJ). mAb 84H10 recognizing ICAM-1 and mAb MHM23 recognizing CD18 were provided by Dr. Stephen Shaw (National Institutes of Health, Bethesda, MD).

Culture of HDMEC. HDMEC were isolated from neonatal foreskins as described previously (11). Experiments were conducted with cells in passages 3-5. HDMEC were incubated with t-RA or DMSO for variable time periods before $\mathrm{TNF} \alpha$ treatment. Expression of CAMs on HDMEC was assessed by ELISA as described previously (12).

Cell adhesion assay. Static adhesion assays to HDMEC were done as described previously (12). Binding assays were performed with Molt-4 cells (derived from a male patient with acute T cell leukemia; American Type Culture Collection, Rockville, MD) or human B-lymphoblastoid JY cells (generously provided by Dr. Jack Strominger, Dana Farber Cancer Institute, Boston, MA), both of which were cultured in RPMI 1640 with $10 \%$ FBS, 2 mM glutamine (Irvine Scientific, Santa Ana, CA), $100 \mathrm{U} / \mathrm{ml}$ penicillin (Gibco Laboratories, Grand Island, NY), $100 \mu \mathrm{g} / \mathrm{ml}$ streptomycin (Gibco Laboratories), and $250 \mu \mathrm{g} / \mathrm{ml}$ amphotericin B (Gibco Laboratories).

Northern blot analysis. Total cellular RNA was isolated by a single-step procedure using RNAzol ${ }^{\mathrm{TM}} \mathrm{B}$ (Biotecx Laboratories, Houston, TX). $25 \mu \mathrm{g}$ of total cellular RNA was fractionated on $1 \%$ agarose-formaldehyde gels, transferred to nylon membranes (Nytran plus; Schleicher \& Schuell, Keene, NH) using an electroblotting chamber (Trans Blot Cell; Bio-Rad Laboratories, Richmond, CA), and then covalently linked by ultraviolet irradiation (UV Stratalinker 1800; Stratagene, La Jolla, CA). Membranes were prehybridized at $60^{\circ} \mathrm{C}$ for $30 \mathrm{~min}$ in Rapid-hyb buffer (Amersham Life Science, Arlington Heights, IL). Hybridization was performed at $60^{\circ} \mathrm{C}$ for $2 \mathrm{~h}$ us- ing the Rapid-hyb buffer containing $\sim 1-3 \times 10^{6} \mathrm{cpm} / \mathrm{ml}$ of $\left[\alpha_{-}{ }^{32} \mathrm{P}\right]-$ labeled DNA probe (specific activity $>10^{9} \mathrm{cpm} / \mu \mathrm{g}$ DNA). Membranes were washed twice with $0.1 \%$ SDS $/ 0.1 \times$ SSC for $20-30 \mathrm{~min}$ at $60^{\circ} \mathrm{C}$ and exposed to $\mathrm{x}$-ray film with intensifying screens at $-70^{\circ} \mathrm{C}$ for 1-2 $\mathrm{d}$. The nylon membranes were stripped with boiled water containing $0.1 \%$ SDS before rehybridization. $\left[\alpha{ }^{-32} \mathrm{P}\right]$-Labeled probes were prepared by using random primer oligonucleotides (rediprime DNA labeling system; Amersham Life Science). A 0.6-kB BglII fragment of the human VCAM-1 cDNA was used as a VCAM-1 probe, and a 0.35 $\mathrm{kB}$ BglII fragment of the human cDNA served as the E-selectin probe (both cDNAs were provided by Dr. T. Venkat Gopal, Otsuka America Pharmaceuticals, Rockville, MD). The ICAM-1 probe consisted of a $0.67-\mathrm{kB}$ StuI fragment of the human ICAM-1 cDNA (provided by Dr. Staunton, Dana-Farber Cancer Institute, Boston, MA) (13).

Reporter constructs. The $-288 /+20$ bp VCAM-1 chloramphenicol acetyl transferase (CAT) construct was generously provided by Dr. Douglas Dean (Washington University, St. Louis, MO) and has been characterized previously (14). The $-1162 /+1$ ICAM-1 CAT (pBS-CAT-P) construct has been described previously (15).

Nuclear run-on assay. HDMEC were pretreated with either DMSO or $8 \times 10^{-5} \mathrm{M} \mathrm{t}$-RA for $20 \mathrm{~h}$ before addition of TNF $\alpha(300 \mathrm{U} / \mathrm{ml})$. After $24 \mathrm{~h}$, cells were harvested by scraping, transferred to microfuge tubes, and pelleted $\left(2,000 \mathrm{rpm}, 5 \mathrm{~min}, 4^{\circ} \mathrm{C}\right)$. Nuclei were prepared by resuspension of the cells in $1 \mathrm{ml}$ ice-cold NP-40 lysis buffer $(10 \mathrm{mM}$ Tris- $\left.\mathrm{HCl}, \mathrm{pH} 7.4 ; 10 \mathrm{mM} \mathrm{NaCl} ; 3 \mathrm{mM} \mathrm{MgCl}_{2} ; 0.5 \% \mathrm{NP}-40\right)$, harvested by centrifugation $\left(2,000 \mathrm{rpm}, 5 \mathrm{~min}, 4^{\circ} \mathrm{C}\right)$, resuspended in $200 \mu \mathrm{lglyc}-$ erol storage buffer (50 mM Tris- $\mathrm{HCl}, \mathrm{pH} 8.3 ; 5 \mathrm{mM} \mathrm{MgCl}_{2} ; 0.1 \mathrm{mM}$ EDTA; $40 \%$ glycerol) and stored in liquid $\mathrm{N}_{2}$.

Plasmids containing cDNA for either human VCAM-1 or glyceraldehyde phosphate dehydrogenase as an irrelevant transcript control were restriction linearized, denatured, neutralized with $6 \times$ SSC, and spotted onto prewet reinforced nitrocellulose strips (Optitran; Schleicher \& Schuell). Each slot contained $5 \mu \mathrm{g}$ DNA and was washed once with $500 \mu 16 \times$ SSC. Membrane strips were dried overnight on Whatman filter paper and then baked under vacuum for $2 \mathrm{~h}$ at $80^{\circ} \mathrm{C}$ and stored wrapped in plastic.

To label RNA being transcribed, $200 \mu \mathrm{l} 2 \times$ reaction buffer (10 $\mathrm{mM}$ Tris- $\mathrm{HCl}, \mathrm{pH} 8.0 ; 5 \mathrm{mM} \mathrm{MgCl}$; $0.3 \mathrm{M} \mathrm{KCl}, 1 \mathrm{mM}$ ATP, $1 \mathrm{mM}$ CTP, $1 \mathrm{mM}$ GTP, $5 \mathrm{mM}$ DTT) and $10 \mu \mathrm{l}$ of ${ }^{32}$ P-labeled $\alpha$ UTP (DuPont, Wilmington, DE) $(3,000 \mathrm{Ci} / \mathrm{mmol})$ were added to each sample of nuclei (containing $\sim 3 \times 10^{6}$ nuclei). After termination of the reaction, RNA precipitated from the aqueous phase and resuspended in $1 \mathrm{ml}$ TES (10 mM [ $N$-tris(hydroxymethyl)methyl-2-aminoethanesulfonic acid], $\mathrm{pH}$ 7.4, $10 \mathrm{mM}$ EDTA, 0.2\% SDS) $+1 \mu \mathrm{l}$ RNasin ribonuclease inhibitor with rocking for $30 \mathrm{~min}$ at room temperature. Radioactive counts per sample were then normalized with TES in $1 \mathrm{ml}$. Hybridization solution contained $1 \mathrm{ml}$ count-normalized RNA solution and 1 $\mathrm{ml} \mathrm{TES} / 0.6 \mathrm{M} \mathrm{NaCl}$. Hybridization was carried out at $65^{\circ} \mathrm{C}$ for $36 \mathrm{~h}$. Membrane strips were then washed with $25 \mathrm{ml} 2 \times$ SSC, placed in heat-sealable bags, and subjected to autoradiography for $1-3 \mathrm{~d}$ at $-80^{\circ} \mathrm{C}$.

Transient transfection of reporter gene constructs and analysis of CAT expression. HDMEC were transiently transfected with CATbased reporter gene constructs as described previously $(16,17) .32 \mathrm{~h}$ after transfection, control transfectants were left untreated (solvent) and test transfectants received $8 \times 10^{-5} \mathrm{M}$ of t-RA. $66 \mathrm{~h}$ after transfection, transfectants were left unstimulated (media change) or received $500 \mathrm{U} / \mathrm{ml} \mathrm{TNF} \alpha$ for $16 \mathrm{~h}$. Cells were then harvested and assayed for CAT expression as described previously (17). As an internal control for transfection efficiency, $3 \mu \mathrm{g}$ of a pSV- $\beta$-galactosidase control vector (Promega, Madison, WI) were cotransfected in each set of experiments. $\beta$-Galactosidase activity was determined by ELISA using the Enzyme Assay System from Promega. Amounts of lysates used for CAT activity analysis were normalized for $\beta$-galactosidase activity.

Preparation of nuclear extracts and gel mobility shift analysis. Confluent EC cultures were treated with TNF $\alpha(500 \mathrm{U} / \mathrm{ml})$ for $2 \mathrm{~h}$ after preincubation with $8 \times 10^{-5} \mathrm{M}$ t-RA for $24 \mathrm{~h}$. In vitro translated 
nuclear proteins were extracted as described previously $(17,18)$. The oligonucleotide wt-NF- $\mathrm{kB} / \mathrm{VCAM}$ was synthesized to encompass the two NF-кB-like sites (in boldface) at positions $-77 \mathrm{bp}$ and $-63 \mathrm{bp}$ of the human VCAM-1 promoter: 5'-CTGCCCTGGGTTTCCCCTTGAAGGGATTTCCCTCCGCCTCTGCAACAAGCTCGAGATCCTATG-3'. The oligonucleotide wt-NF-кB/ICAM was synthesized to encompass the NF- $\mathrm{kB}$-like site (in boldface) at positions $-186 \mathrm{bp}$ of the human ICAM-1 promoter: 5'-TTAGCTTGGAAATTCCGGAGCTCGAGATCCTATG-3'. The underlined sequence represents an unrelated tail sequence added to serve as template for synthesis of the second strand. Radiolabeled double-stranded DNA was synthesized by annealing an oligonucleotide complementary to the $3^{\prime}$ end of the sequence listed above (underlined; 5'-CATAGGATCTCG-3') and by extending the second strand with Klenow fragment, $50 \mu \mathrm{Ci}$ of $\left[\alpha^{-32} \mathrm{P}\right] \mathrm{dCTP}$ (Amersham Life Science), unlabeled dATP, dGTP, and dTTP (Pharmacia Biotech, Piscataway, NJ) followed by the addition of unlabeled dCTP to ensure completion of the second strand. All oligonucleotides were synthesized by the Emory University Microchemistry Facility. Cold double-stranded DNA was made identically, except that unlabeled dCTP was substituted for labeled dCTP. The DNA binding reaction was performed for $30 \mathrm{~min}$ at room temperature in a volume of $20 \mu \mathrm{l}$ as described previously (17). Samples were subjected to electrophoresis on a native $4 \%$ polyacrylamide gel for $4 \mathrm{~h}$ at $120 \mathrm{~V} / 10-12 \mathrm{~A}$.

Statistics. For statistical analysis, Student's $t$ tests were performed. $P$ values $>0.05$ were not considered significant.

\section{Results}

$t$-RA prevents $T N F \alpha$-induced $V C A M-1$ cell surface expression on HDMEC. To explore whether preincubation with t-RA modulates the cytokine-induced expression of CAM on HDMEC, VCAM-1, E-selectin, and ICAM-1 protein expressions were evaluated by cell-ELISA technique and flow-cytometric analysis. For dose-response studies, HDMEC were either exposed to different concentrations of t-RA or solvent only for $24 \mathrm{~h}$, and were subsequently stimulated with TNF $\alpha$ at a concentration of $500 \mathrm{U} / \mathrm{ml}$ (Fig. 1) for $16 \mathrm{~h}$ (VCAM-1, ICAM-1) or $6 \mathrm{~h}$ (E-selectin). The applied concentration and duration of $\mathrm{TNF} \alpha$ had been shown previously to maximally induce the CAMs studied $(12,19)$. Pretreatment with t-RA did not significantly affect TNF $\alpha$-induced ICAM-1 or E-selectin expression (Fig. 1, $A$ and $B$ ) or their baseline expression on HDMEC (data not shown). However, cytokine-mediated VCAM-1 induction was reduced by half at concentrations of 3-4 $\times 10^{-5} \mathrm{M}$ t-RA, and complete inhibition was typically seen with t-RA preincubation of $5-8 \times 10^{-5} \mathrm{M}$ for $24 \mathrm{~h}$ (Fig. $1 \mathrm{C}$ ). In addition, we found that as little as a 4-h t-RA pretreatment was sufficient to inhibit VCAM-1 induction by $>60 \%$, whereas complete inhibition was consistently observed after t-RA preincubation between 16 and $24 \mathrm{~h}$ (data not shown).

For time course studies, concentrations of $8 \times 10^{-5} \mathrm{M}$ t-RA were applied for $24 \mathrm{~h}$ before TNF $\alpha$ stimulation. Cytokinemediated ICAM-1 expression was not significantly affected by t-RA pretreatment at any given time point (Fig. $2 A$ ). The cytokine-induced profile of rapid and transient E-selectin expression was nearly identical in both control and t-RA preincubated cells (Fig. 2 B). However, VCAM-1 induction was completely prevented by t-RA pretreatment at all time points studied (Fig. $2 C$ ), demonstrating a selective inhibition of cytokine-mediated induction of VCAM-1. Cell surface data assessed by cell ELISA were consistent with flow-cytometric analyses of CAM expression on HDMEC (data not shown). These data demonstrate that t-RA treatment differentially
A

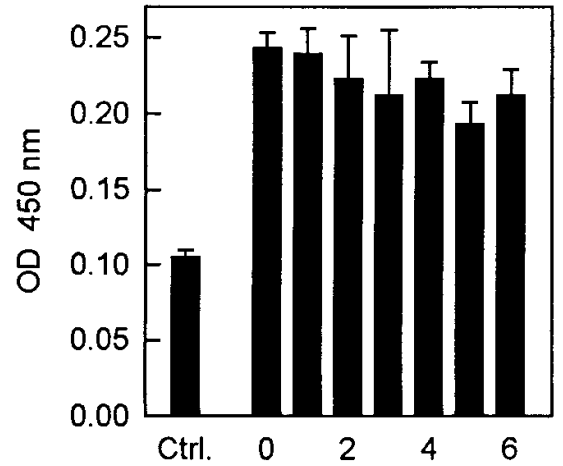

ICAM-1

B

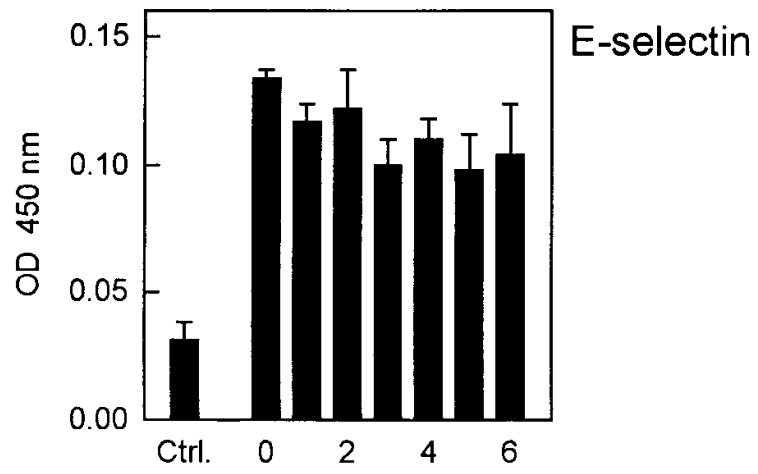

C

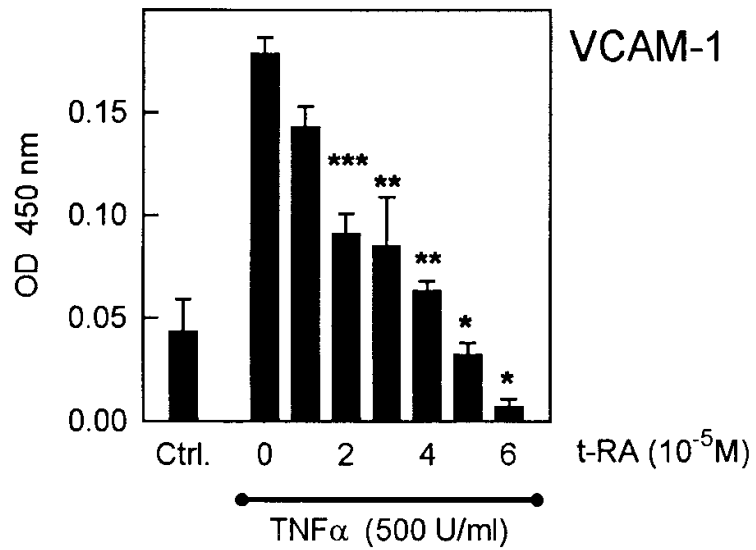

Figure 1. Treatment with t-RA specifically prevents TNF $\alpha$-induced VCAM-1 cell surface in a concentration-dependent fashion (ELISA). Representative cell ELISA for ICAM-1 $(A)$, E-selectin $(B)$, and VCAM-1 $(C)$ expression on HDMEC. EC were left untreated (Ctrl., first bar), or were preincubated with increasing concentrations of t-RA before TNF $\alpha$ stimulation $(500 \mathrm{U} / \mathrm{ml})$ for either $16 \mathrm{~h}$ (ICAM-1, VCAM-1) or $6 \mathrm{~h}$ (E-selectin). Values are expressed as OD $450 \mathrm{~nm}$ and represent the mean \pm SD of quadruplicate analyses. Statistical analyses of OD values obtained from t-RA pretreated cells (third to eighth bars) versus those which did not receive t-RA treatment before TNF $\alpha$ stimulation (second bar) were determined on the basis of three independent experiments. ${ }^{* * *} P<0.05$; $* * P<0.01 ; * P<0.001$; Student's $t$ test.

modulates the cytokine-regulated expression of CAM on microvascular EC with preferential inhibition of the VCAM-1 induction.

$t$-RA pretreatment reduces VCAM-1-dependent cell binding to $T N F \alpha$-treated HDMEC. To establish that t-RA pretreatment specifically inhibits VCAM-1-dependent cell bind- 

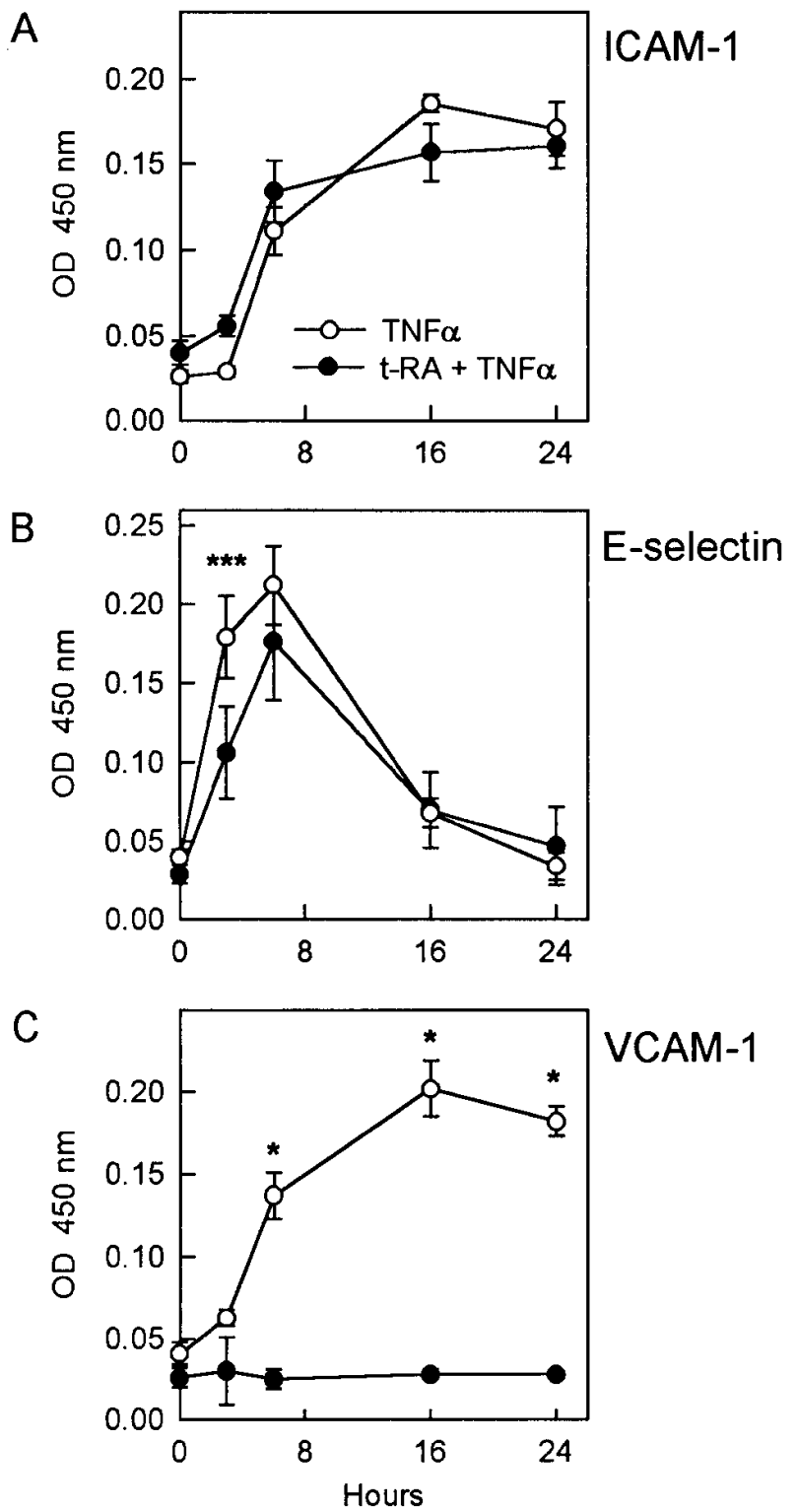

Figure 2. Effects of t-RA preincubation on the kinetics of TNF $\alpha$ induced CAM expression on HDMEC. Representative cell ELISA for ICAM-1 $(A)$, E-selectin $(B)$, and VCAM-1 $(C)$ expression on HDMEC. EC were stimulated with a single dose of TNF $\alpha(500 \mathrm{U} / \mathrm{ml})$ for different time periods $(3,6,16$, and $24 \mathrm{~h})$ either after $24 \mathrm{~h}$ of preincubation with solvent only (open circles) or $8 \times 10^{-5} \mathrm{M}$ of t-RA (filled circles). Values are expressed as OD $450 \mathrm{~nm}$ and represent the mean \pm SD of quadruplicate analyses. Statistical analyses of OD values obtained from t-RA pretreated cells (filled circles) versus those which did not receive t-RA treatment (open circles) before TNF $\alpha$ stimulation were determined on the basis of three independent experiments. ${ }^{* * *} P<0.05 ; * P<0.001$; Student's $t$ test.

ing, we performed cell adhesion assays using either the $\mathrm{T}$ cell line Molt-4 (Fig. 3) or the B cell line JY (data not shown) and HDMEC monolayers. Molt-4 cells have been shown previously to adhere to EC preferentially via a VCAM-1-dependent pathway by expressing $\alpha 4 \beta 1$-integrin receptor (20). JY cells appear to be $\beta 1$ integrin subunit negative (21) and have been shown previously to bind to TNF $\alpha$-stimulated EC almost entirely through an LFA-1/ICAM-1-dependent mechanism

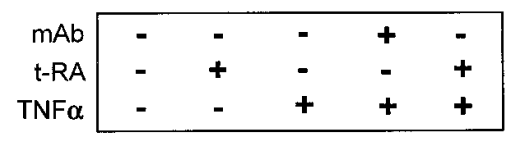

Figure 3. Preincubation with t-RA inhibits VCAM-1-dependent, but not ICAM-1-

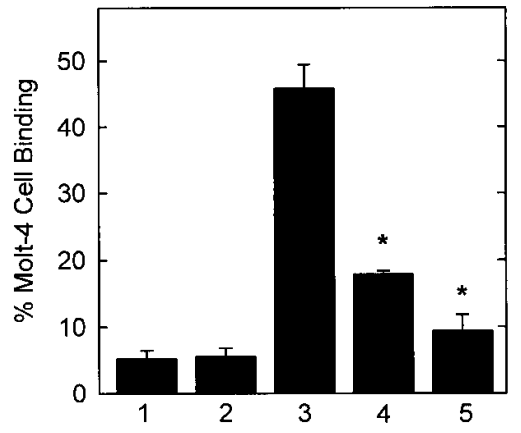

dependent, cell binding to TNF $\alpha$-stimulated HDMEC. Representative cell adhesion assays for Molt-4 VCAM-1dependent cell binding to unstimulated (lanes 1 and 2) and TNF $\alpha$ treated HDMEC (lanes 3-6). Cell adhesion to stimulated HDMEC $(500 \mathrm{U} / \mathrm{ml}$ of $\mathrm{TNF} \alpha)$ was determined under different experimental conditions: after cytokine stimulation alone (lane 3), after preincubation with blocking mAb P3C4 recognizing VCAM-1 (lane 4), and after $24 \mathrm{~h}$ treatment with t-RA $\left(8 \times 10^{-5} \mathrm{M}\right.$, lane 5). Values are expressed as percentage of Molt- 4 cell binding and represent the mean \pm SD of six determinations. Statistical analyses of values obtained from cells which were either pretreated with t-RA (lane 5) or were incubated with blocking mAb (lane 4) versus those cells which were stimulated with TNF $\alpha$ only (lane 3 ) were determined on the basis of two independent experiments. $* P<0.001$, Student's $t$ test.

(22). HDMEC were pretreated with $8 \times 10^{-5} \mathrm{M}$ of t-RA or solvent only for $24 \mathrm{~h}$, and were either left unstimulated or were subsequently induced with $500 \mathrm{U} / \mathrm{ml} \mathrm{TNF} \alpha$ for $16 \mathrm{~h}$. TNF $\alpha$ treatment markedly increased both Molt-4 cell binding to HDMEC monolayers and this increase in Molt-4 cell binding was significantly inhibited through preincubation with blocking anti-VCAM-1 antibody. The TNF $\alpha$-induced increase in Molt-4 cell binding was almost completely inhibited by pretreatment with t-RA. On the other hand, the cytokine-mediated increase in JY cell binding was essentially unchanged by t-RA pretreatment (data not shown). Blocking anti-CD18 mAb entirely abrogated JY cell adhesion to stimulated HDMEC, confirming that JY cells adhere to stimulated HDMEC in a VCAM-1-independent manner (data not shown). Together, these data indicate that t-RA pretreatment inhibits VCAM-1dependent, but not CD18/ICAM-1-dependent, cell binding to TNF $\alpha$-treated HDMEC.

The differential modulation of $T N F \alpha$-induced $C A M$ expression by $t-R A$ pretreatment is reflected at steady state $m R N A$ levels. To determine whether the effects of t-RA treatment on $\mathrm{TNF} \alpha$-mediated CAM induction are reflected at steady state mRNA levels, Northern blot analyses of HDMEC mRNA were performed (Fig. 4). HDMEC were either exposed to t-RA or solvent only for $24 \mathrm{~h}$ and were subsequently stimulated with $\mathrm{TNF} \alpha$ for $8 \mathrm{~h}$. Consistent with the cell surface data, Northern blot analyses revealed a preferential inhibition of cytokineinduced VCAM-1 mRNA accumulation by t-RA pretreatment. $\mathrm{TNF} \alpha$ treatment markedly increased steady state mRNA levels of VCAM-1 and ICAM-1 as well as E-selectin. E-selectin mRNA levels, although consistently lower after t-RA incubation, still showed a marked increase after TNF $\alpha$ stimulation despite t-RA preincubation. However, TNF $\alpha$-induced VCAM-1 mRNA accumulation was virtually completely prevented by t-RA pretreatment. These findings demonstrate that the t-RA effects on induced CAM expression by EC are re- 


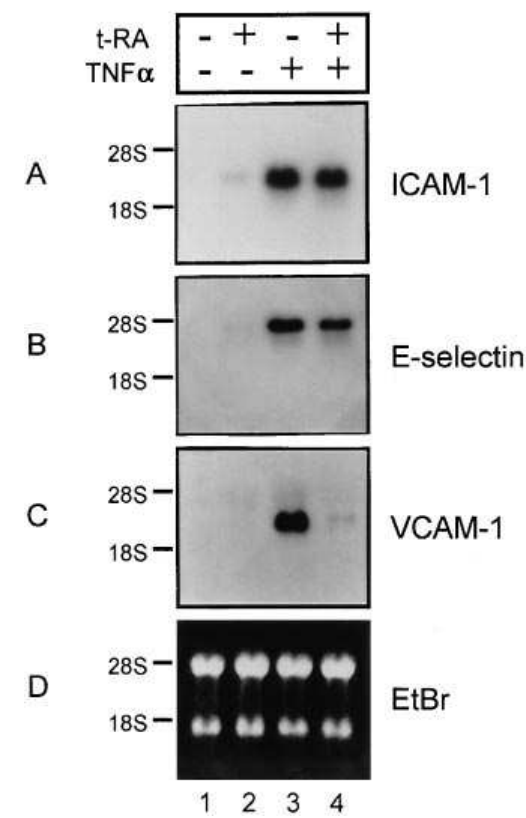

Figure 4. t-RA treatment prevents accumulation of VCAM-1, but not ICAM-1 or E-selectin, mRNA in TNF $\alpha$ stimulated HDMEC. Representative of two separate Northern blot analyses for ICAM-1

$(A)$, E-selectin $(B)$, and VCAM-1 $(C)$ mRNA expression in HDMEC. $D$ displays an image of the ethidium bromide $(E t B r)$-stained nylon membrane to demonstrate even loading and transfer. Unstimulated EC were left untreated (solvent, lane 1 ) or incubated with $8 \times 10^{-5} \mathrm{M}$ of t-RA (lane 2). Similarly, mRNA of TNF $\alpha$ induced HDMEC (500

$\mathrm{U} / \mathrm{ml}, 8 \mathrm{~h}$ ) was analyzed after pretreatment with solvent only (lane 3 ) or t-RA $\left(8 \times 10^{-5} \mathrm{M}\right.$, lane 4$)$ for $24 \mathrm{~h}$.

flected in mRNA steady state levels, suggesting that this differential regulation is potentially mediated at the transcriptional level.

Treatment with $t-R A$ inhibits transcriptional activation of the human VCAM-1 promoter by $T N F \alpha$. Since the difference in cytokine-induced CAM expression after pretreatment with t-RA was reflected in steady state mRNA levels, we next analyzed whether this differential modulation of adhesion molecule induction in HDMEC was regulated at the level of gene transcription. Therefore, we performed nuclear run-on assays and transcriptional activation studies using CAT reporter constructs containing promoter regions of the VCAM- 1 and ICAM-1 gene. For nuclear run-on assays, HDMEC were stimulated with t-RA alone, TNF $\alpha$ alone, or treated with TNF $\alpha$ after t-RA pretreatment. Unstimulated HDMEC expressed minimal basal transcriptional activity of the VCAM-1 gene (Fig. $5 a$ ) and TNF $\alpha$ treatment resulted in a marked increase in

Figure 5. Pretreatment with t-RA suppresses TNF $\alpha$-induced transcriptional activation of VCAM-1 (a) Nuclear run-on: HDMEC were pretreated with t-RA $\left(8 \times 10^{-5} \mathrm{M} \times 20 \mathrm{~h}\right)$ and then stimulated with $\mathrm{TNF} \alpha(300 \mathrm{U} / \mathrm{ml} \times 4 \mathrm{~h})$. Run-on transcripts generated from isolated nuclei from untreated cells $(C)$, cells treated with t-RA $(t-R A)$ or $\mathrm{TNF} \alpha(T N F)$ alone, or pretreated with t-RA before TNF $\alpha(T N F+$ $t-R A$ ) treatment were hybridized to $5 \mu \mathrm{g}$ of VCAM-1 or glyceraldehyde phosphate dehydrogenase $(G A P D H)$ cDNA immobilized on nitrocellulose membranes. (b) t-RA suppresses TNF $\alpha$-induced transcriptional activation of VCAM-1-based, but not ICAM-1-based, CAT reporter constructs in HDMEC. Representative duplicate assays for CAT activity utilizing a $-1162 /+1$ bp ICAM- $1(A)$ or a $-288 /+20$ bp VCAM-1 construct $(C)$ as reporter plasmids for transient transfections $\left(C M,{ }^{14} \mathrm{C}\right.$-labeled chloramphenicol substrate; 1-Ac-CM and 3-Ac-CM, monoacetylated products). Treatment and stimulation were performed as indicated. Composite data of CAT expression from HDMEC transfected with either the ICAM-1 construct
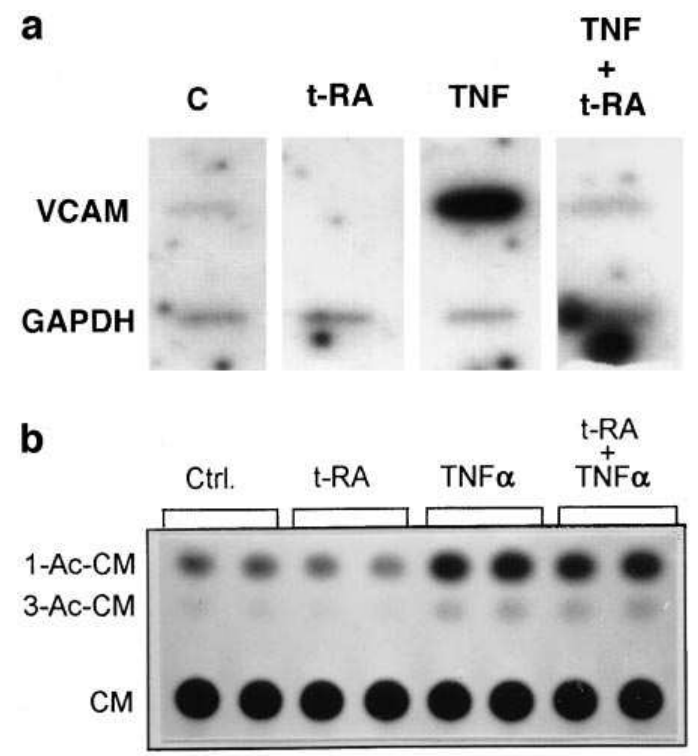

A

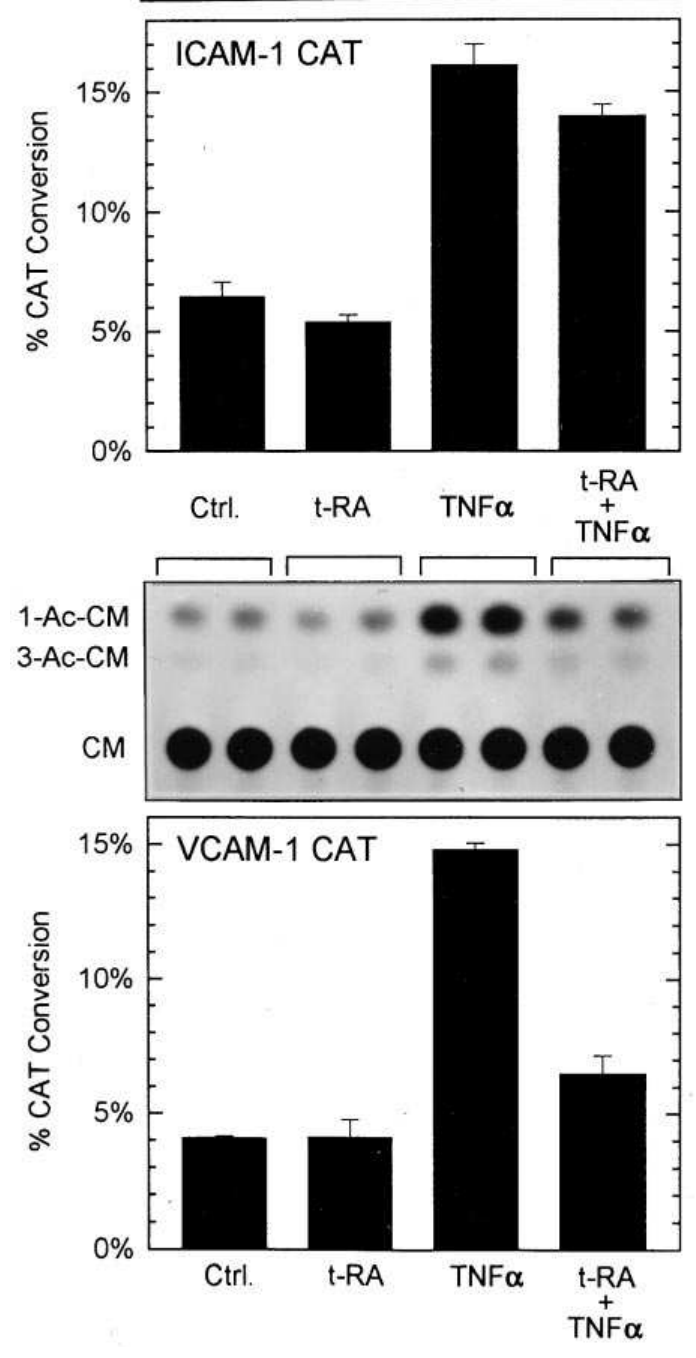

B

C

D

$(B)$ or the VCAM-1 construct $(D)$ are displayed below (expressed as percent conversion of ${ }^{14} \mathrm{C}$-labeled chloramphenicol to acetylated products). Values represent the mean $\pm \mathrm{SD}$ of the depicted duplicate assays. Cells were transfected as detailed in Methods. CAT conversion was normalized according to transfection efficiency. Results were confirmed by at least three independent sets of duplicate experiments using different cell isolations and plasmid preparations. 

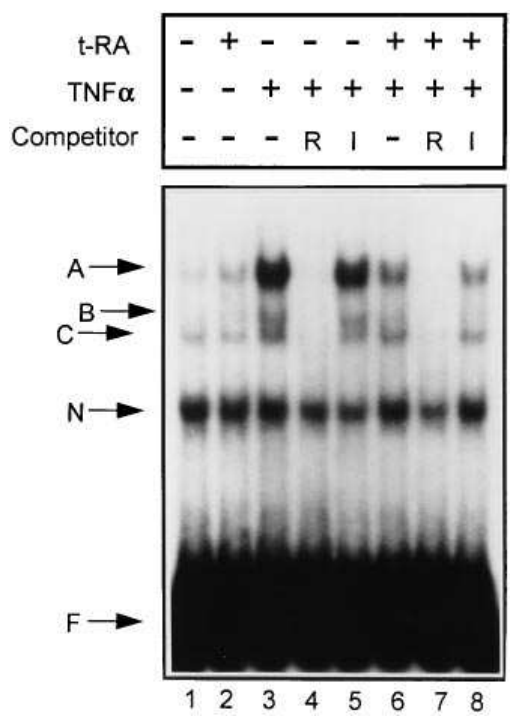

Figure 6. t-RA preincubation inhibits TNF $\alpha$ induced NF- $\mathrm{KB}$ motifdependent binding to the human VCAM-1 promoter in HDMEC. Representative EMSAs using nuclear protein extracts of untreated (lanes 1 and 2) and $\mathrm{TNF} \alpha$-treated (lanes 3-8) HDMEC and a radiolabeled doublestranded DNA probe corresponding to the NF- $\kappa$ B motifs of the VCAM-1 promoter (sequence detailed in Methods). t-RA pretreatment and stimulation were performed as indicated. Equivalent amounts of nuclear proteins and radiolabeled probe were used for each sample. The formation of specific complexes is indicated on the left (bands $A, B$, and $C$ ). $N$ represents a nonspecific band, and $F$ indicates the free labeled DNA probe. Binding reactions were performed and analyzed four times using different cell preparations and provided consistent results. Competitor was used at a concentration of 100 molar excess $(R$, relevant: cold identical DNA, lanes 2 and 7; $I$, irrelevant: unrelated $-706 /-288$ bp fragment of the VCAM-1 promoter, lanes 5 and 8 ).

VCAM-1 gene transcription. Additionally, the minimal basal transcriptional activity of VCAM-1 in untreated HDMEC was inhibited by t-RA alone and t-RA pretreatment almost totally inhibited the TNF $\alpha$-induced increases in VCAM-1 gene transcription.

For transcriptional activation studies, CAT constructs were transiently transfected into HDMEC, and subsequently the respective CAT activities in response to TNF $\alpha$ either after preincubation with t-RA or solvent were analyzed (Fig. $5 b$ ). t-RA alone did not discernibly change the baseline expression activity of either the ICAM-1 or the VCAM-1 CAT construct. $\mathrm{TNF} \alpha$ treatment led to marked transcriptional activation of both the ICAM-1 and VCAM-1 reporter genes. While preincubation with t-RA did not significantly affect the TNF $\alpha$ mediated transactivation of the ICAM-1 promoter, the VCAM-1 CAT construct was consistently repressed by $\sim 60 \%$. These findings provide evidence that the specific and selective inhibition of cytokine-mediated VCAM-1 expression through t-RA is regulated in part at the level of gene transcription.

$t-R A$ treatment selectively inhibits $T N F \alpha$-induced $N F-\kappa B$ element-dependent binding to the human VCAM-1 promoter. Since previous studies have established that two adjacent NF$\kappa \mathrm{B}$ sites, located at coordinates -77 and $-63 \mathrm{bp}$ with respect to the VCAM-1 promoter transcription initiation site, are required for cytokine-induced VCAM-1 transcription $(14,23)$, the question arose whether t-RA reduces $\mathrm{TNF} \alpha$-mediated VCAM-1 gene transcription via mechanisms involving NF- $\mathrm{B}$ transcription factor activation or NF- $\mathrm{B}$-dependent DNAprotein complex formation. Therefore, we performed electrophoretic mobility shift assays (EMSAs) using nuclear extracts of untreated and TNF $\alpha$-treated HDMEC, either preincubated with t-RA or solvent only, and a radiolabeled double-stranded

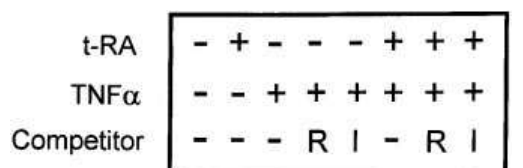

Figure 7. t-RA treatment does not affect $\mathrm{TNF} \alpha$-induced NF-кB motif-dependent binding to the human

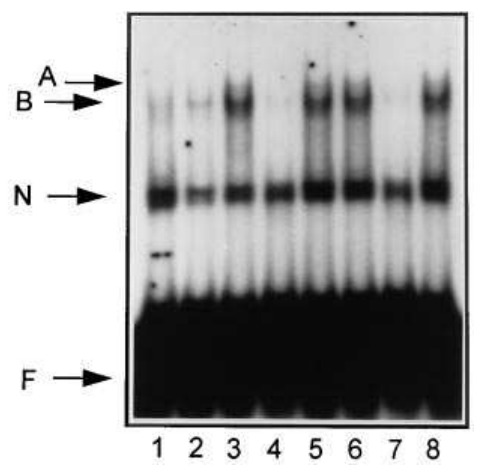

ICAM-1 promoter in HDMEC. Representative EMSAs using nuclear protein extracts of untreated (lanes 1 and 2) and $\mathrm{TNF} \alpha$-treated (lanes 3-8) HDMEC and a radiolabeled double-stranded DNA probe corresponding to the NF-кB motif of the ICAM-1 promoter (sequence detailed in Methods). The formation of specific com-

plexes is indicated on the left (bands $A$ and $B$ ). Binding reactions were performed and analyzed three times using different cell preparations with consistent results. Competitor was used at a concentration of 100 molar excess ( $R$, relevant: cold identical DNA, lanes 2 and 7; $I$, irrelevant: unrelated 30-bp fragment of the ICAM-1 promoter, lanes 5 and 8 ).

DNA probe corresponding to the exact VCAM-1 tandem $\mathrm{NF}-\kappa \mathrm{B}$ sites (Fig. 6). TNF $\alpha$ treatment induced specific complex formation with the NF- $\mathrm{B}$ sites of the VCAM-1 promoter. Specificity was confirmed by competition with excess cold identical DNA, but not with irrelevant DNA. However, pretreatment with $\mathrm{t}-\mathrm{RA}$ significantly inhibited specific $\mathrm{NF}-\mathrm{k}$ DNA binding activity. These observations suggest that the inhibition of $\mathrm{TNF} \alpha$-induced VCAM- 1 gene transcription by t-RA is mediated in part by its effects on induced NF-кBdependent DNA-protein complex formation.

To examine whether NF-кB-dependent binding activity to this ICAM-1 site was inhibited by t-RA in a fashion similar to that seen with the tandem NF-кB sites of the VCAM-1 promoter, we performed EMSAs in which the functional ICAM-1 $\mathrm{NF}-\kappa \mathrm{B}$ sequence was used as a specific probe (24, Fig. 7). $\mathrm{TNF} \alpha$ treatment induced specific complex formation with the $\mathrm{NF}-\kappa \mathrm{B}$ site of the ICAM-1 promoter that was competed with excess cold identical DNA. In contrast to the findings obtained with the NF-кB VCAM-1 promoter probe, pretreatment with t-RA had little or no effect on specific NF- $\mathrm{B}$-dependent binding activity to the ICAM-1 NF- $\mathrm{B}$ probe. Taken together, these data demonstrate selective t-RA-mediated inhibition of NF-кB-dependent complex formation within the TNF $\alpha$ response region of the VCAM-1, but not the ICAM-1, promoter.

\section{Discussion}

In approaches to determine modes of retinoid action in inflammatory processes, effects of t-RA on the cytokine-induced expression of VCAM-1, E-selectin, and ICAM-1 on dermal microvascular EC were studied. We here report that pretreatment with t-RA prevents TNF $\alpha$-mediated VCAM- 1 induction, but not ICAM-1 or E-selectin upregulation on cultured HDMEC. This differential susceptibility of the induced adhesion molecule expression to t-RA on microvascular EC appears 
to be regulated in part at the level of gene transcription as determined by transcriptional activation studies and EMSA analyses.

RA and its synthetic derivatives have been shown to be highly effective as both topical and systemic treatment of inflammatory skin diseases (6), such as psoriasis and acne vulgaris. The underlying mechanisms of retinoid action in the modulation of inflammatory responses are not well defined. The modes of retinoid action in immune responses have been demonstrated previously in part to involve regulatory effects on cytokine synthesis and receptor presentation in macrophages, lymphocytes, and other immunocompetent cells (9). As an additional central factor in immune responses, the regulated expression of CAMs is critical for the function and integrity of all tissues, particularly for leukocyte recognition and transmigration through the endothelium (1). The time-dependent induction of VCAM-1, E-selectin, and ICAM-1 by a number of proinflammatory signals represents a common feature of cutaneous inflammatory disorders. Specifically, VCAM-1 and E-selectin are viewed as important participants relevant to the pathogenesis of psoriasis by allowing initial trafficking of memory T-lymphocytes into psoriatic lesions (25). Therefore, the modulation and inhibition of CAM expression on EC and leukocytes may represent a potential target of retinoid action at sites of inflammation, particularly those characterized by mononuclear infiltrates.

The regulation of ICAM- 1 by retinoids has been studied previously. In transformed cell lines, retinoids have been shown to induce ICAM-1 expression or augment its upregulation by other known inducers of ICAM-1 $(26,27)$. However, in primary cell cultures such as epidermal keratinocytes or EC, retinoids have not been found to induce ICAM-1 in significant amounts $(28,29)$. Consistent with our observations, studies on the cytokine-induced ICAM-1 expression in dermal microvascular EC did not reveal inhibitory effects with the retinoid compound acitretin (30). Conversely, retinoids have been found to inhibit other parameters of EC activation. Specifically, RA downregulates the TNF $\alpha$-induced increase in tissue factor protein and mRNA levels in a concentration-dependent manner in human EC (31). In addition, t-RA has been shown to inhibit TNF $\alpha$ - and LPS-mediated events in other cell types as well. RA reduces the expression of procoagulant activity by human peripheral blood mononuclear cells stimulated with endotoxin $(32,33)$.

With respect to their therapeutic effects in cutaneous inflammatory disorders, retinoids may exert their biologic actions in part by targeting the cytokine-induced regulation of CAMs on microvascular EC. Therefore, we studied the effects of t-RA pretreatment on the cytokine-induced expression of VCAM-1, ICAM-1, and E-selectin on HDMEC. Unlike ICAM-1 or E-selectin induction, the regulated expression of VCAM-1 is completely suppressed after preincubation with t-RA for $24 \mathrm{~h}$. These observations indicate that VCAM-1 is particularly susceptible to t-RA treatment with regard to its cytokine-regulated induction in the context of cultured microvascular EC. We have further demonstrated the functional significance of the t-RA effect on VCAM-1 expression on HDMEC and that transcriptional control mechanisms appear to mediate in part the differential modulation of TNF $\alpha$-induced CAM expression by t-RA. In preliminary studies, we observed that the induction of VCAM-1 expression in large vessel derived human umbilical vein EC (HUVEC) is not inhibited by t-RA pretreat- ment. These studies further buttress biologic differences among EC from different organ sources. Distinct differences between HDMEC and HUVEC have been demonstrated previously with regard to their immunologic phenotypes (34) and their regulation of cell adhesion proteins $(17,19)$. The clarification of these differences is critical when using EC as models and investigative tools in studies of vascular biologic and pathophysiologic processes.

At the molecular level, two families of nuclear retinoid receptor proteins, the retinoic acid receptors (RARs) and the retinoid X receptors ( $\mathrm{RXRs}$ ), have been implicated in many retinoid effects (10). Unlike the direct activation of target genes by RA and its receptors via corresponding RA-response elements, inhibitory effects on the rate of gene transcription by RA, often referred to as trans-repression, frequently appear to involve indirect mechanisms (9). Retinoid receptors can form nonproductive heteromultimers with members of other transcription factor families. This formation prevents binding to the designated sites in a gene's regulatory regions which are necessary for their transcriptional activation (35). Retinoid receptors may also negatively regulate gene expression via interacting directly with octamer binding sites (36).

Our observations suggest that the transcriptional inhibition of the VCAM-1 promoter by t-RA is mediated in part by its effects on activation of a specific NF- $\mathrm{B} \mathrm{B}$-dependent complex formation. NF- $\mathrm{KB}$ transcription factors recognize specific decameric consensus sequences in many genes involved in acute phase response and immune function (37). Major components of NF-кB-dependent gene regulation are the cytoplasmic retention of inactive NF-кB subunits through interaction with precursor proteins or a group of inhibitor proteins, the IkBs (38) and the selective binding of different homo- or heterodimeric complexes to slight variations of the NF- $\mathrm{KB}$ motif in promoter regions $(39,40)$. Previous studies have established that two adjacent NF-кB binding sites, located at positions -77 and -63 bp with respect to the VCAM-1 promoter transcription initiation site, are required for cytokine-induced VCAM-1 transcription (14, 23). Before these studies, information regarding RA-mediated effects on the activation or inhibition of NF- $\mathrm{B}$ transcription factors was limited. A functionally relevant increase in DNA binding activity of $\mathrm{NF}-\kappa \mathrm{B}$ factors to corresponding sites in the MHC class I promoter in response to RA was observed in embryonal carcinoma cells (41). Yet, transcriptional activation studies using diverse NF- $\mathrm{B}$ consensus sequences in different neuroblastoma cell lines did not reveal NF-кB DNA binding activity in response to RA, although treatment with $\mathrm{TNF} \alpha$ and PMA, both known activators of $\mathrm{NF}-\kappa \mathrm{B}$ proteins, resulted in specific binding activity (42). Our studies show that t-RA inhibits specific and selective proteinDNA complex formation with the NF- $\mathrm{B}$ sites of the human VCAM-1 promoter, but not with the functional NF- $\mathrm{BB}$ site of the ICAM-1 promoter within TNF $\alpha$-treated EC. Since the NF-кB sites are necessary for both TNF $\alpha$-induced VCAM-1 and ICAM-1 expression $(14,23,24)$, these findings further emphasize the functional significance of these motifs in the RAmediated inhibition of the regulated VCAM-1 gene transcription, and also provide a rational explanation for the lack of t-RA-mediated inhibition of ICAM-1 promoter activation.

The question thus arises as to which molecular mechanisms mediate selective transcriptional inhibition within the context of different NF-кB-regulated promoters (43). Our findings suggest that the differential effects depend on selective disrup- 


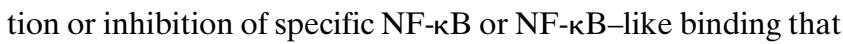
is necessary for transcription of the VCAM-1 gene, while the formation of complexes which mediate gene transcription of the ICAM-1 gene may not be affected. According to this model, t-RA pretreatment may selectively inhibit activated NF- $\kappa \mathrm{B}$-dependent protein-DNA binding to the critical regions of the VCAM-1 promoter, but because of distinct differences in the trans-activating complexes formed, this effect may not be seen with the critical NF-кB region of the ICAM-1 gene. This selectivity and specificity may also rely on the formation of distinct NF-кB complexes with members from different transcription factor families which interact with the VCAM-1 or ICAM-1 NF-кB sequences $(39,40)$. Conceivably, t-RA treatment may inhibit activation of distinct transcription factors other than NF- $\mathrm{B}$ required for transactivation via the tandem NF-кB motif of the VCAM-1 promoter. As a result, specific DNA binding required for transcriptional activation of the VCAM-1 gene may be destabilized and disrupted. Alternatively, t-RA may induce activation of transcription factors which may form nonproductive complexes with distinct $\mathrm{NF} \kappa \mathrm{B}$ subunits in that they prevent binding with the NF-кB sites of the VCAM-1 promoter, analogous to the formation of nonproductive heteromultimers of retinoid receptor proteins with AP-1 transcription factors (35).

Our studies are comparable with those which have examined effects of antioxidants on CAM expression in EC $(44,45)$. Consistent with our observations, E-selectin and ICAM-1 inductions were not significantly affected by antioxidant pretreatment. Additionally, this differential regulation was linked to transcriptional regulatory mechanisms involving NF-kB activation. Since neither of these studies has addressed the issue of selective transcriptional inhibition within the context of different NF-кB-regulated promoters, one can only speculate whether antioxidants may render similar effects as seen in our transcriptional activation and DNA binding studies. Potentially, retinoids and antioxidants use identical or similar signaling pathways to mediate differential inhibitory effects on endothelial CAM regulation. This hypothesis is supported by studies revealing antioxidative properties of retinol and derivatives at physiologic and pharmacologic concentrations (46).

We have demonstrated previously that HDMEC differ from many of their large vessel counterparts both phenotypically and functionally $(11,17,19,34)$ and it is not particularly surprising that additional differences are being described. The differential response to retinoids does not appear to be due to a global lack of response to t-RA in HUVEC, since previous studies have demonstrated that t-RA treatment of HUVEC antagonizes specific TNF-induced effects (31). The differential response to t-RA could also suggest that HDMEC may express novel patterns of NF-кB/Rel family proteins that may in part explain the distinct pattern of VCAM-1 gene expression and response to retinoids. Preliminary studies from our laboratories provide support for this possibility in that, although HDMEC express levels of p65 and rel A that are comparable to those detected in HUVEC, they constitutively express much higher levels of rel B (Paxton, L.L., unpublished observation). How these differences may relate to the differential response to t-RA is a focus of ongoing study.

In summary, our observations demonstrate that t-RA differentially affects the regulated CAM expression by cultured dermal microvascular EC. The preferential inhibition of TNF $\alpha-$ induced VCAM-1 upregulation is mediated in part through transcriptional control mechanisms involving the activation of NF-кB-dependent complex formation. By selectively suppressing VCAM-1 expression and consequent function in leukocyte-EC recognition and localization, this pharmacologic activity may provide a potential basis by which retinoids exert their biological effects at sites of inflammation in vivo.

\section{Acknowledgments}

The authors are grateful to Dr. Wayner for providing mAb P3C4, to Dr. Wolitzky for providing mAb 1D6, and to Dr. Shaw for providing mAb $84 \mathrm{H} 10$ and mAb MHM23. We gratefully thank Dr. Gopal for providing the VCAM-1 and the E-selectin cDNA, as well as Dr. Staunton for providing the ICAM-1 cDNA. We are grateful to Dr. Dean for providing the VCAM-1 CAT construct, and to Dr. Strominger for providing the JY cells.

This work was supported by National Institutes of Health grant Public Health Service grants AR36632 (R.A. Swerlick), AR39632 (T.J. Lawley), and AR42687 (S.W. Caughman), the Emory Skin Diseases Research Center grant, by Deutsche Forschungsgemeinschaft grant Gi 229/1-1 (J. Gille), and by a Dermatology Foundation Research fellowship (J. Gille).

\section{References}

1. Carlos, T.M., and J.M. Harlan. 1994. Leukocyte-endothelial adhesion molecules. Blood. 84:2068-2101.

2. Rothlein, R., M.L. Dustin, S.D. Marlin, and T.A. Springer. 1986. A human intercellular adhesion molecule (ICAM-1) distinct from LFA-1. J. Immunol. 137:1270-1274.

3. Bevilacqua, M.P., J.S. Pober, D.L. Mendrick, R.S. Cotran, and M.A. Gimbrone, Jr. 1987. Identification of an inducible endothelial-leukocyte adhesion molecule. Proc. Natl. Acad. Sci. USA. 84:9238-9242.

4. Rice, G.E., J.M. Munro, and M.P. Bevilacqua. 1990. Inducible cell adhesion molecule 110 (INCAM-110) is an endothelial receptor for lymphocytes. A CD11/CD18-independent adhesion mechanism. J. Exp. Med. 171:1369-1374.

5. Springer, T.A. 1994. Traffic signals for lymphocyte recirculation and leukocyte emigration: the multistep paradigm. Cell. 76:301-314.

6. Larsen, F.G., F. Nielsen-Kudsk, P. Jakobsen, K. Weismann, and K. Kragballe. 1992. Pharmacokinetics and therapeutic efficacy of retinoids in skin diseases. Clin. Pharmacokinet. 23:42-61.

7. Gudas, L.J. 1994. Retinoids and vertebrate development. J. Biol. Chem. 269:15399-15402.

8. Lotan, R. 1991. Retinoids as modulators of tumor cells invasion and metastasis. Semin. Cancer Biol. 2:197-208.

9. Gudas, L.J., M.B. Sporn, and A.B. Roberts. 1994. Cellular biology and biochemistry of the retinoids. In The Retinoids. Biology, Chemistry, and Medicine. M.B. Sporn, A.B. Roberts, and D.S. Goodman, editors. Raven Press, Ltd., New York. 443-520.

10. Mangelsdorf, D.J., K. Umesono, and R.M. Evans. 1994. The retinoid receptors. In The Retinoids. Biology, Chemistry, and Medicine. M.B. Sporn, A.B. Roberts, and D.S. Goodman, editors. Raven Press, Ltd., New York. 319-349.

11. Kubota, Y., H.K. Kleinman, G.R. Martin, and T.J. Lawley. 1988. Role of laminin and basement membrane in the morphological differentiation of human endothelial cells into capillary-like structures. J. Cell Biol. 107:1589-1598.

12. Sepp, N.T., J. Gille, L.J. Li, S.W. Caughman, T.J. Lawley, and R.A. Swerlick. 1994. A factor in human plasma permits persistent expression of E-selectin by human endothelial cells. J. Invest. Dermatol. 102:445-450.

13. Staunton, D.E., S.D. Marlin, C. Stratowa, M.L. Dustin, and T.A. Springer. 1988. Primary structure of ICAM-1 demonstrates interaction between members of the immunoglobulin and integrin supergene families. Cell. 52:925933.

14. Iademarco, M.F., J.J. McQuillan, G.D. Rosen, and D.C. Dean. 1992. Characterization of the promoter for vascular cell adhesion molecule-1 (VCAM-1). J. Biol. Chem. 267:16323-16329.

15. Degitz, K., L.J. Li, and S.W. Caughman. 1991. Cloning and characterization of the $5^{\prime}$-transcriptional regulatory region of the human intercellular adhesion molecule 1 gene. J. Biol. Chem. 266:14024-14030.

16. Sambrook, J., E.F. Fritsch, and T. Maniatis. 1989. Molecular Cloning: A Laboratory Manual. Cold Spring Harbor Laboratory, Cold Spring Harbor, NY.

17. Gille, J., R.A. Swerlick, T.J. Lawley, and S.W. Caughman. 1996. Differential regulation of vascular cell adhesion molecule- 1 gene transcription by tumor necrosis factor-alpha and interleukin-1alpha in dermal microvascular endothelial cells. Blood. 87:211-217.

18. Dignam, J.D., R.M. Lebovitz, and R.G. Roeder. 1983. Accurate tran- 
scription initiation by RNA polymerase II in a soluble extract from isolated mammalian nuclei. Nucleic Acids Res. 11:1475-1489.

19. Swerlick, R.A., K.H. Lee, L.-J. Li, N.T. Sepp, S.W. Caughman, and T.J. Lawley. 1992. Regulation of vascular cell adhesion molecule 1 on human dermal microvascular endothelial cells. J. Immunol. 149:698-705.

20. Carlos, T.M., B.R. Schwartz, N.L. Kovach, E. Yee, M. Rosa, L. Osborn, G. Chi-Rosso, B. Newman, R. Lobb, et al. 1990. Vascular cell adhesion molecule-1 mediates lymphocyte adherence to cytokine-activated cultured human endothelial cells [published erratum appears in Blood. 1990. 76:2420]. Blood. 76:965-970.

21. Stupack, D.G., C. Shen, and J.A. Wilkins. 1992. Induction of alpha v beta 3 integrin-mediated attachment to extracellular matrix in beta 1 integrin (CD29)-negative B cell lines. Exp. Cell Res. 203:443-448.

22. Dustin, M.L., and T.A. Springer. 1988. Lymphocyte function-associated antigen-1 (LFA-1) interaction with intercellular adhesion molecule-1 (ICAM-1) is one of at least three mechanisms for lymphocyte adhesion to cultured endothelial cells. J. Cell Biol. 107:321-331.

23. Neish, A.S., A.J. Williams, H.J. Palmer, M.Z. Whitley, and T. Collins. 1992. Functional analysis of the human vascular cell adhesion molecule 1 promoter. J. Exp. Med. 176:1583-1593.

24. Ledebur, H.C., and T.P. Parks. 1995. Transcriptional regulation of the intercellular adhesion molecule-1 gene by inflammatory cytokines in human endothelial cells. Essential roles of a variant NF-kappa B site and p65 homodimers. J. Biol. Chem. 270:933-943.

25. Wakita, H., and M. Takigawa. 1994. E-selectin and vascular cell adhesion molecule-1 are critical for initial trafficking of helper-inducer/memory $\mathrm{T}$ cells in psoriatic plaques. Arch. Dermatol. 130:457-463.

26. Bouillon, M., P. Tessier, R. Boulianne, R. Destrempe, and M. Audette. 1991. Regulation by retinoic acid of ICAM-1 expression on human tumor cell lines. Biochim. Biophys. Acta. 1097:95-102.

27. Wang, Z., Y. Cao, C.M. D'Urso, and S. Ferrone. 1992. Differential susceptibility of cultured human melanoma cell lines to enhancement by retinoic acid of intercellular adhesion molecule 1 expression. Cancer Res. 52:4766-4772.

28. Meunier, L., K. Bohjanen, J.J. Voorhees, and K.D. Cooper. 1994. Retinoic acid upregulates human Langerhans cell antigen presentation and surface expression of HLA-DR and CD11c, a beta 2 integrin critically involved in T-cell activation. J. Invest. Dermatol. 103:775-779.

29. Imcke, E., Z. Ruszczak, A. Mayer-da Silva, M. Detmar, and C.E. Orfanos. 1991. Cultivation of human dermal microvascular endothelial cells in vitro: immunocytochemical and ultrastructural characterization and effect of treatment with three synthetic retinoids. Arch. Dermatol. Res. 283:149-157.

30. Detmar, M., S. Tenorio, U. Hettmannsperger, Z. Ruszczak, and C.E. Orfanos. 1992. Cytokine regulation of proliferation and ICAM-1 expression of human dermal microvascular endothelial cells in vitro. J. Invest. Dermatol. 98: 147-153.

31. Ishii, H., S. Horie, K. Kizaki, and M. Kazama. 1992. Retinoic acid counteracts both the downregulation of thrombomodulin and the induction of tissue factor in cultured human endothelial cells exposed to tumor necrosis factor. Blood. 80:2556-2562.

32. Conese, M., P. Montemurro, R. Fumarulo, D. Giordano, S. Riccardi, M. Colucci, and N. Semeraro. 1991. Inhibitory effect of retinoids on the generation of procoagulant activity by blood mononuclear phagocytes. Thromb. Haemost.
66:662-665

33. Barstad, R.M., M.J. Hamers, R.W. Stephens, and K.S. Sakariassen 1995. Retinoic acid reduces induction of monocyte tissue factor and tissue factor/factor VIIa-dependent arterial thrombus formation. Blood. 86:212-218.

34. Swerlick, R.A., K.H. Lee, T.M. Wick, and T.J. Lawley. 1992. Human dermal microvascular endothelial but not human umbilical vein endothelial cells express CD36 in vivo and in vitro. J. Immunol. 148:78-83.

35. Schule, R., P. Rangarajan, N. Yang, S. Kliewer, L.J. Ransone, J. Bolado, I.M. Verma, and R.M. Evans. 1991. Retinoic acid is a negative regulator of AP1-responsive genes. Proc. Natl. Acad. Sci. USA. 88:6092-6096.

36. Felli, M.P., A. Vacca, D. Meco, I. Screpanti, A.R. Farina, M. Maroder, S. Martinotti, E. Petrangeli, L. Frati, and A. Gulino. 1991. Retinoic acid-induced down-regulation of the interleukin-2 promoter via cis-regulatory sequences containing an octamer motif. Mol. Cell. Biol. 11:4771-4778.

37. Baeuerle, P.A. and T. Henkel. 1994. Function and activation of NFkappa B in the immune system. Annu. Rev. Immunol. 12:141-179.

38. Liou, H.C., and D. Baltimore. 1993. Regulation of the NF-kappa B/rel transcription factor and I kappa B inhibitor system. Curr. Opin. Cell. Biol. 5: 477-487.

39. Kunsch, C., S.M. Ruben, and C.A. Rosen. 1992. Selection of optimal kappa B/Rel DNA-binding motifs: interaction of both subunits of NF-kappa B with DNA is required for transcriptional activation. Mol. Cell. Biol. 12:44124421 .

40. Perkins, N.D., R.M. Schmid, C.S. Duckett, K. Leung, N.R. Rice, and G.J. Nabel. 1992. Distinct combinations of NF-kappa B subunits determine the specificity of transcriptional activation. Proc. Natl. Acad. Sci. USA. 89:15291533.

41. Segars, J.H., T. Nagata, V. Bours, J.A. Medin, G. Franzoso, J.C. Blanco, P.D. Drew, K.G. Becker, J. An, T. Tang, et al. 1993. Retinoic acid induction of major histocompatibility complex class I genes in NTera-2 embryonal carcinoma cells involves induction of NF-kappa B (p50-p65) and retinoic acid receptor beta-retinoid X receptor beta heterodimers. Mol. Cell. Biol. 13:6157-6169.

42. Korner, M., N. Tarantino, O. Pleskoff, L.M. Lee, and P. Debre. 1994 Activation of nuclear factor kappa B in human neuroblastoma cell lines. J. Neurochem. 62:1716-1726

43. Collins, T., M.A. Read, A.S. Neish, M.Z. Whitley, D. Thanos, and T. Maniatis. 1995. Transcriptional regulation of endothelial cell adhesion molecules: NF-kappa B and cytokine-inducible enhancers. FASEB (Fed. Am. Soc. Exp. Biol.) J. 9:899-909.

44. Marui, N., M.K. Offermann, R. Swerlick, C. Kunsch, C.A. Rosen, M. Ahmad, R.W. Alexander, and R.M. Medford. 1993. Vascular cell adhesion molecule-1 (VCAM-1) gene transcription and expression are regulated through an antioxidant-sensitive mechanism in human vascular endothelial cells. J. Clin. Invest. 92:1866-1874.

45. Weber, C., W. Erl, A. Pietsch, M. Strobel, H.W. Ziegler-Heitbrock, and P.C. Weber. 1994. Antioxidants inhibit monocyte adhesion by suppressing nuclear factor-kappa B mobilization and induction of vascular cell adhesion molecule-1 in endothelial cells stimulated to generate radicals. Arterioscler. Thromb. 14:1665-1673.

46. Livrea, M.A., and L. Packer. 1994. Vitamin A as an antioxidant in vitro and in vivo. In Retinoids: From Basic Science to Clinical Applications. M.A. Livrea and G. Vidali, editors. Birkhauser Verlag, Basel. 293-304. 